\title{
Relating soil moisture and air temperature to evapotranspiration fluxes during inter-storm periods at a Mediterranean experimental site
}

\author{
Antonia LONGOBARDI ${ }^{1}$, Elina KHAERTDINOVA ${ }^{2 *}$ \\ ${ }^{1}$ Department of Civil Engineering, University of Salerno, Via Ponte Don Melillo, Fisciano 84084, Italy; \\ ${ }^{2}$ Department of Production Safety and Industrial Ecology, Ufa State Aviation Technical University, Ufa 450000, Russia
}

\begin{abstract}
The assessment of the water losses by actual evapotranspiration plays a very important role in water resources management, especially in particular environments suffering soil water stresses and water shortages. The rationales of this study are the scarcity of experimental data, the difficulties in the measurement of direct and continuous evapotranspiration fluxes, and the switching between controls by climate and soil water availability. The temporal patterns of observed soil moisture and air temperature of over three years at an experimental site in southern Italy have been analysed to investigate the relation between them and the actual evapotranspiration volume, estimated using the soil water budget method. To this end, an event-based empirical analysis has been performed, exploring the relation between the mentioned variables. One of the major findings of the explorative phase is the qualitative and quantitative identification of the switching between climate and soil water balance as the controls over actual evapotranspiration at the experimental site. This threshold process has then been modelled at the event and sub-event scale, establishing simple empirical equations to predict actual evapotranspiration losses as a function of soil water content. Multilevel-recorded data also allowed the investigation of the importance of soil depth.
\end{abstract}

Keywords: evapotranspiration; soil moisture; event scale; empirical analysis; Italy

Citation: Antonia LONGOBARDI, Elina KHAERTDINOVA. 2015. Relating soil moisture and air temperature to evapotranspiration fluxes during inter-storm periods at a Mediterranean experimental site. Journal of Arid Land, 7(1): 27-36. doi: 10.1007/s40333-014-0075-8

The assessment of the evapotranspiration component of the water cycle assumes a very important role for water resources management, weather forecast, agricultural planning and further research issues. The quantification of actual evapotranspiration, i.e. the effecttive rather than potential soil water content loss, is even more important in arid and semi-arid environments and in countries suffering soil water stresses and water shortages, such as countries in the Mediterranean basin (Rana and Katerji, 2000). Simulation also has important scientific applications given the great difficulties in direct and continuous measurement of evapotranspiration fluxes, especially with changes in spatial and temporal scales, climate condi- tions and vegetation types. From this point of view, there are numerous scientific contributions reporting on the application of different evapotranspiration assessment models in different regions of the world and for different climate and land cover conditions $(\mathrm{Su}-$ leiman and Hoogenboom, 2007; Douglas et al., 2009; Trajkovic and Kolakovic, 2009; Tabari, 2010). Undoubtedly, instrumentation for monitoring micrometeorological variables, whose peculiarities, pros and cons are well discussed by Wilson et al. (2001), has rapidly become common and popular, but experimental data are still scarce in the spatial domain and are occasionally difficult to acquire due to topographical complexity, requiring a more intensive

\footnotetext{
"Corresponding author: Elina KHAERTDINOVA (E-mail: ElinaSagitovna@yandex.ru) 
modelling effort (Brena Naranjo et al., 2011). From a modelling perspective, exporting the results gained from investigation at a particular experimental site to a different site is very difficult. The actual evapotranspiration process is a non-linear one, which is primarily driven by two major variables: the atmospheric evaporative power and the available soil water content. The former exerts the so-called climate control, whereas the latter exerts the so-called soil water balance control, which is also dependent on the typical vegetation cover. The influence of climate and soil controls alternate during the hydrological year; however, if no experimental data are available, it is difficult to assess the alternation modality, and it is not possible to confirm that this modality is the same for different sites (Fisher et al., 2008).

The scarcity of data, the non-linearity of the process and the operational difficulty of estimating the actual rather than potential rate of evapotranspiration, are thus simultaneously the motivations and the focus of this empirical study. The analysis undertaken is generally derived from observed data, in particular soil moisture and air data, and the relationships between these variables and the loss by actual evapotranspiration. Some similar examples are already given in the literature for other climatic conditions and vegetation (Brandes and Wilcox, 2000; Verhoef et al, 2006; Nan et al, 2011); this case study characterizes the typical Mediterranean climate.

Because evapotranspiration is a phenomenon of predominant importance in the absence of precipitation events, approximately 30 inter-storm periods were selected and analysed at different scales of temporal aggregation in this study.

At the event scale, using non-dimensional analysis, the dependence between the water content of the soil and the actual evapotranspiration was observed to be quite strong. On the one hand, this consideration highlights the strong control exercised by the soil in a typically Mediterranean climate; on the other hand, it suggests the calibration of simple empirical relationships to enable an assessment of the hydrological losses that occur during a fixed time interval. The implications of these analyses appear to be rather important for particular hydrological applications, such as irrigation, in which the fixed initial soil moisture conditions, and thus the knowledge of the volume of water that will be lost, can be an important element for operation planning for irrigation.

For a more general purpose, it might be necessary to know the dynamics of variables other than soil water content $(\theta)$ at finer scales, such as daily. For this purpose, each selected event has been modelled as a negative exponential function. The rate of the soil water content depletion appears to have a quite evident seasonal connotation as well as a dependency on the initial conditions in terms of $\theta$. The similarities found in the analyses conducted at the event scale lead to the observation that the conditions at the experimental site in question and the rate of depletion are strongly related to the evapotranspired volume. With the initial conditions expressed in terms of $\theta$, these correspondences enable the determination of both the volume of water lost to evapotranspiration and the average speed with which the loss occurs. Multilevel, recorded data also allowed the investigation of the importance of soil depth, highlighting differences and similarities.

In summary, this study focuses on the following points: (1) analysis of the relations between observed air temperature, soil water content and actual evapotranspiration for a particular experimental site in a Mediterranean climate; (2) identification of the mechanism controlling the switching between climate control and soil water balance control on actual evapotranspiration losses; and (3) identification of simple and empirical relationships to predict actual evapotranspiration losses as a function of soil water content at the experimental site.

\section{Material and methods}

\subsection{Experimental site and data}

The experimental plot is located in southern Italy, on the campus of the University of Salerno, and has an area of $450 \mathrm{~m}^{2}$. The terrain features a smooth $35^{\circ}$ slope, with a flat area in the upper portion, which is contiguous to a car park. Runoff from the car park is diverted from the experimental site. The slope is bounded by a $1-\mathrm{m}$ retaining wall at the toe. The vegetation consists of perennial lawn grass. The collected samples show a layered soil profile: the first layer ranges from 0 to $20 \mathrm{~cm}$ and is classified as gra- 
vel with silt and clay, and the second layer ranges from 20 to $60 \mathrm{~cm}$ and is classified as clay with silt sand.

Meteorological and soil moisture measurements began in October 2004 and ended in May 2008. Precipitation and air temperature were measured by an automatic weather station every 10 minutes. Six EasyAG (Sentek Pty. Ltd., South Australia) capacitance probes were installed to continuously measure soil water content every 10 minutes. The probe consists of an access tube, $3.2 \mathrm{~cm}$ in diameter, where two sensors (2.65 $\mathrm{cm}$ in diameter) are inserted at 10 and 30 $\mathrm{cm}$ below the soil surface. Laboratory calibration was performed based on gravimetric water content determination. The soil moisture measurements have an error of $\pm 2.72 \% \mathrm{~V} / \mathrm{V}$.

Figure 1 plots the precipitation and the soil water content time series at 10 and $30 \mathrm{~cm}$ for the three complete recorded hydrological years (in the Mediterranean region, from October of a particular year to October of the following year), as an illustration of the soil moisture dynamics at the experimental site.

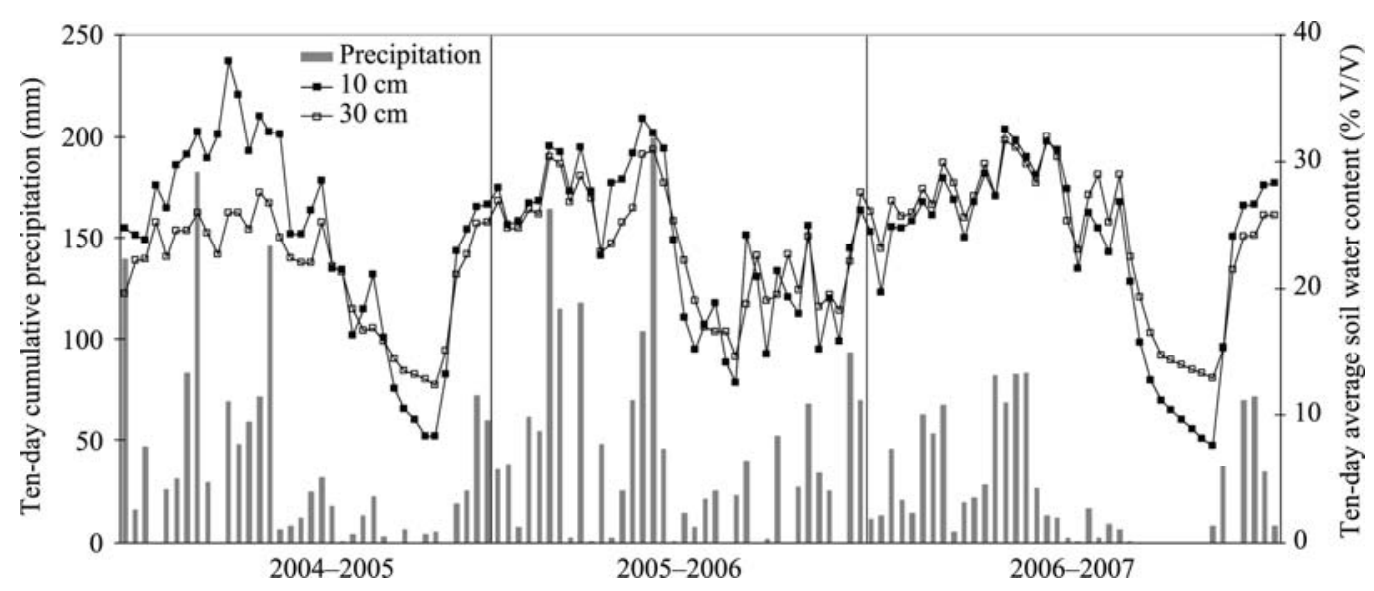

Fig. 1 Soil water content $(10$ and $30 \mathrm{~cm})$ and precipitation recorded time series at the experimental site

The soil water content had two different stationary periods, one corresponding to the winter season, with the greatest soil moisture content, and one corresponding to the summer season, with the lowest soil moisture content. Further discussion of the seasonal soil water dynamics can be found in Longobardi (2008).

The observed variables, precipitation, air temperature and soil water content are related each other through the hydrological cycle processes, in particular, the evapotranspiration process. Evapotranspiration losses are caused by evaporative atmospheric power, which is clearly a function of air temperature, but the losses are also limited by the soil water availability, which is controlled by precipitation occurrence.

\subsection{Aggregated event scale analysis}

As discussed above, an event scale analysis was performed with the objective of quantifying simple, databased, but conceptually meaningful, relationships between soil moisture, air temperature and evapotranspiration volumes. To particularly focus on the rela- tions among the mentioned variables, approximately thirty inter-storm periods, each with a minimum length of five days, were selected from October 2004 to October 2007. For each event, the evapotranspiration volume was estimated using the soil water budget method, which has been widely applied in different climate and vegetation cover contexts (Rana and Katerji, 2000; Wilson et al., 2001; Schume et al., 2004; Shah et al., 2012; Shang, 2012).

The soil water budget is an indirect method for ET assessment because ET is estimated as the residual term of the mass conservation equation:

$$
\mathrm{P}-\mathrm{ET}-\mathrm{R}-\mathrm{D}= \pm \Delta \mathrm{S} \text {. }
$$

Where $\mathrm{P}$ is the precipitation (plus artificial irrigation if any), ET the evapotranspiration, R the surface runoff, $\mathrm{D}$ the deep drainage and $\Delta \mathrm{S}$ the variation in soil water content in the soil layer. Some authors have suggested the elimination of rainy days from the analysis when attempting to investigate the evaporative process: precipitation inputs and the movements of soil water within the soil profile confound estimates of soil water 
content extraction using the soil water budget approach (Wilson et al., 2001). Moreover, during inter-storm periods, Eq. 1 is simplified by the absence of precipitation input $(P=0)$, and consequently, there is no runoff volume $(R=0)$ to be accounted for; thus, ET estimates become:

$$
\mathrm{ET}= \pm \Delta \mathrm{S}+\mathrm{D} .
$$

For the experimental site, the study of the temporal evolution of the profiles of soil moisture (Longobardi et al., 2006) established that there is a low permeability layer at a depth of $300-500 \mathrm{~m}$, indicating that the drainage component is also negligible. Equation 2 can be further simplified as:

$$
\mathrm{ET}= \pm \Delta \mathrm{S}= \pm\left(\theta_{0}-\theta_{\mathrm{f}}\right) \text {, }
$$

meaning that the evapotranspired volume (ET), during a particular event, is comparable to the loss of water content over the same time interval, between the ini-
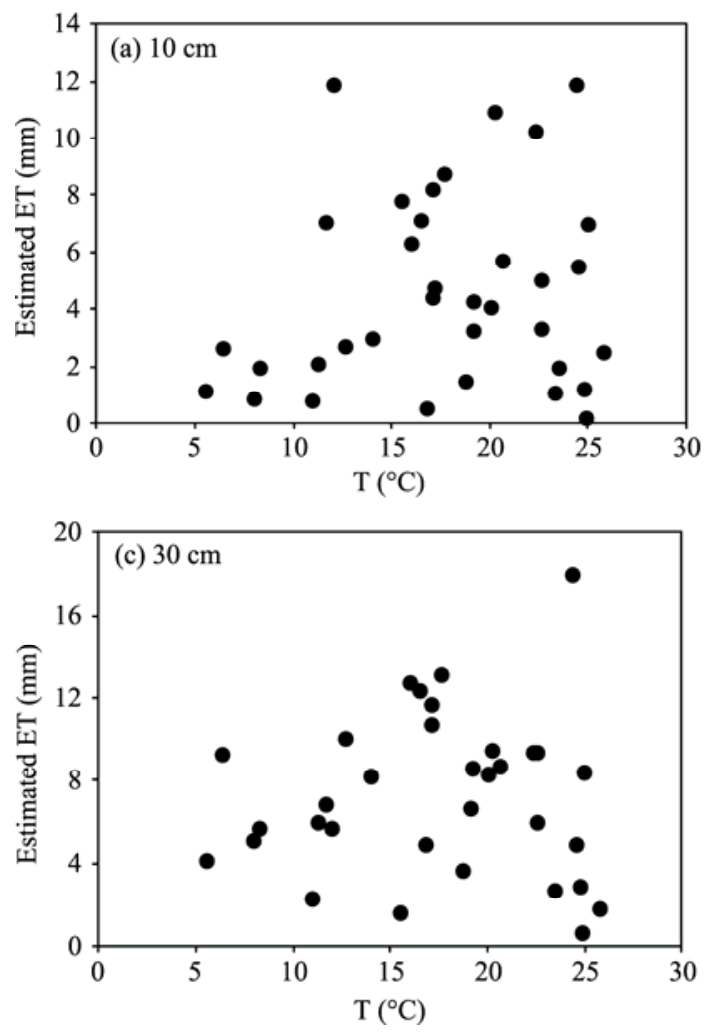

tial time and the final $\theta_{0}$ and $\theta_{\mathrm{f}}$. To express the magnitudes of Eq. 3 in mm, it becomes:

$$
\mathrm{ET}= \pm \Delta \mathrm{S} \times \mathbf{Z}= \pm\left(\theta_{0}-\theta_{\mathrm{f}}\right) \times \mathrm{Z} .
$$

Where $\mathrm{z}$ represents the soil depth, expressed in $\mathrm{mm}$. As a simplification, the soil water content measured at 10 and $30 \mathrm{~cm}$ is considered to be constant over the range of soil depth.

\section{Results and discussion}

\subsection{Aggregated event scale: preliminary empirical analysis}

For each inter-storm event, the initial soil moisture content $\left(\theta_{0}, \%\right)$, the average air temperature during the event $\left(\mathrm{T},{ }^{\circ} \mathrm{C}\right)$ and the cumulative evapotranspiration volume estimated at the event scale $(\mathrm{ET}, \mathrm{mm})$ are plotted in Fig. 2 for the 10 and $30 \mathrm{~cm}$ soil depths.
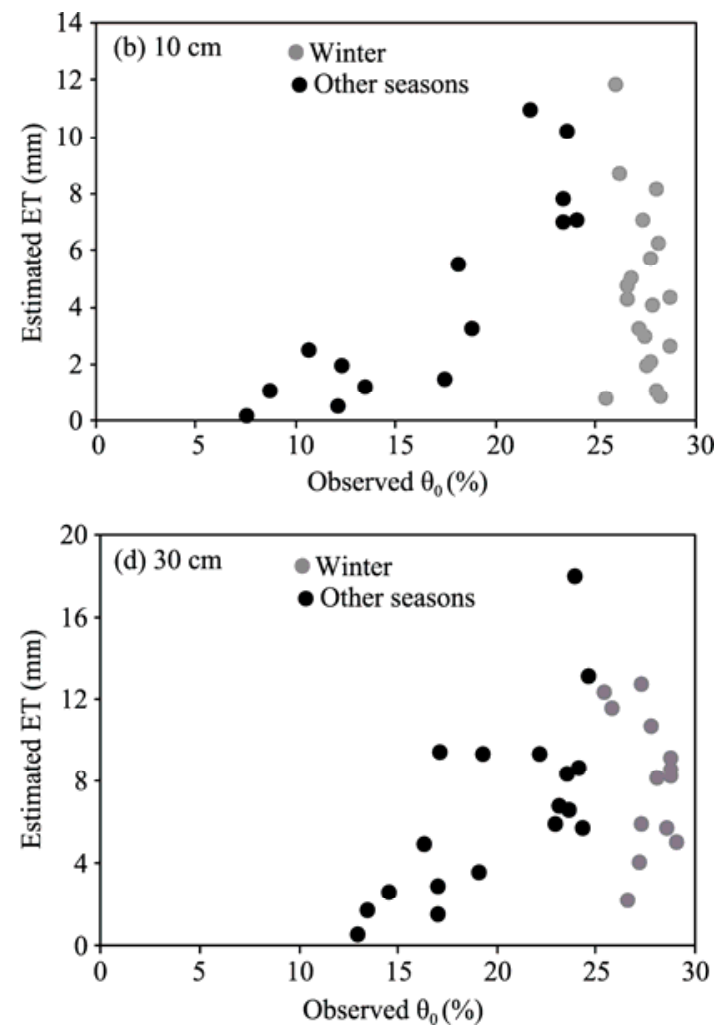

Fig. 2 Scatter plots of observed $\theta_{0}$, average temperature and estimated evapotranspiration for 10 and $30 \mathrm{~cm}$ soil depths

The relationship between ET and the average temperature $(\mathrm{T})$ is not very significant, both at 10 and 30 $\mathrm{cm}$ layers in the soil (Figs. 2a and b). The high dispersion in the scatter plot indicates that the air temperature, and thus the climatic condition, is not the dominant control in the experimental field in question; therefore, an empirical relationship for actual evapotranspiration as a function of $\mathrm{T}$ cannot be easily established.

The dependence of ET on $\theta_{0}$ is instead clearer, particularly in the $10 \mathrm{~cm}$ surface layer (Fig. 2b) and perhaps related to the soil properties. For values less than 
a threshold of approximately $25 \%$, ET values increase with increasing $\theta$, whereas for values larger than such a threshold, the values of ET are highly variable.

The 25\% threshold value approximately corresponds to the literature filed capacity for the investigated soil, a silt loam. When water contents are below the filed capacity, there will be an upward movement of water driven by ET, which would be dependent on water availability (then on $\theta_{0}$ ).

When water contents are above the field capacity, gravitational forces can overcome the capillary ones. In this case, even though the water availability is high,

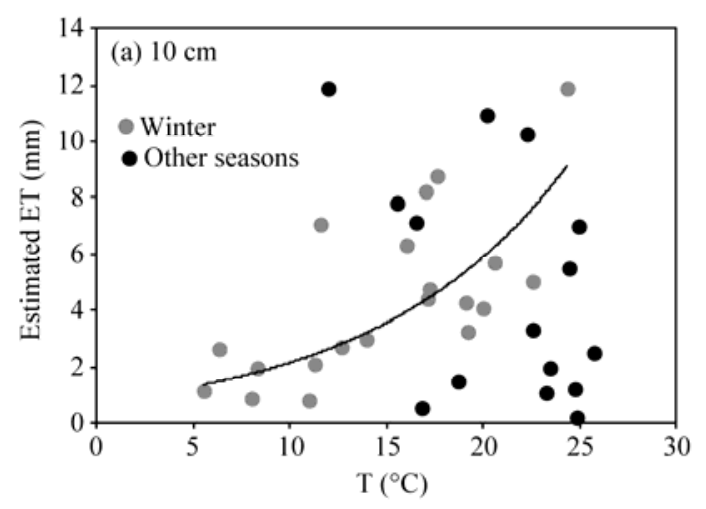

ET losses are not necessarily high. Their magnitude probably depends on the balance between capillary and gravitational forces, related to the plant water uptake mechanism that might be associated with climate factors. The higher values of $\theta$ are generally reached during the winter rainy season, when water availability is at or close to a maximum; thus, the ET is driven by the evaporative power of the air and the temperature of the air itself. For events that occurred during the winter season, the relationship between ET and T, although not particularly significant, is still indicative of a trend of increasing ET with increasing T (Fig. 3).

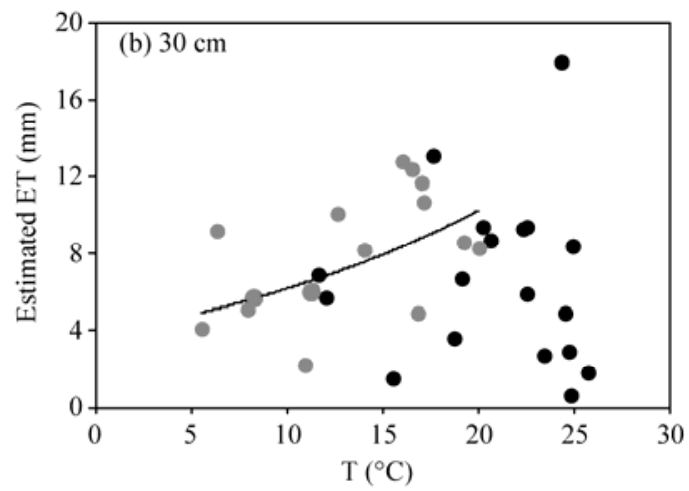

Fig. 3 Scatter plots of observed T versus estimated ET

The same considerations apply to the $30 \mathrm{~cm}$ soil layer (Figs. 2d and 3b), although the relations are weaker, most likely because at greater depths into the soil the process of evapotranspiration is always more limited by the depth of and the loss to the upper soil layer.

\subsection{Continuous soil moisture dynamics: prelimi- nary empirical analysis}

The event scale analysis presented above has a clear benefit when the budget is referred to in an aggregate scale, with the objective of determining the volume lost in terms of the water content during a fixed interval. These operations are typically linked to management problems and the use of water resources in agricultural fields: in the hypothesis of absence of precipitation, being able to predict the volume of evapotranspiration based on the observed value of $\theta_{0}$ allows optimal irrigation procedures to be planned. However, there are other issues with the use and management of water resources, perhaps even more general, that require further analysis from a description of the aggregate scale of events, such as a description of the dynamics of soil moisture during the inter-storm periods.

With this purpose, in a more empirical approach previously used by Khaertdinova and Longobardi (2013a), the initial step is to further examine the dynamics of the previously selected events based on the data. In the analysis of the dynamics, seasonal differences are considered because of the seasonal influence on climate. As will be demonstrated below, the temporal evolution of the events, which will be summarised through a parameter $\alpha$, can be connected to the process of evapotranspiration; the latter has a seasonal connotation, which should also influence the speed of the soil moisture depletion process during the inter-storm periods.

Figure 4 illustrates, as an example, the temporal evolution of inter-storm events for both dry and wet seasons. 

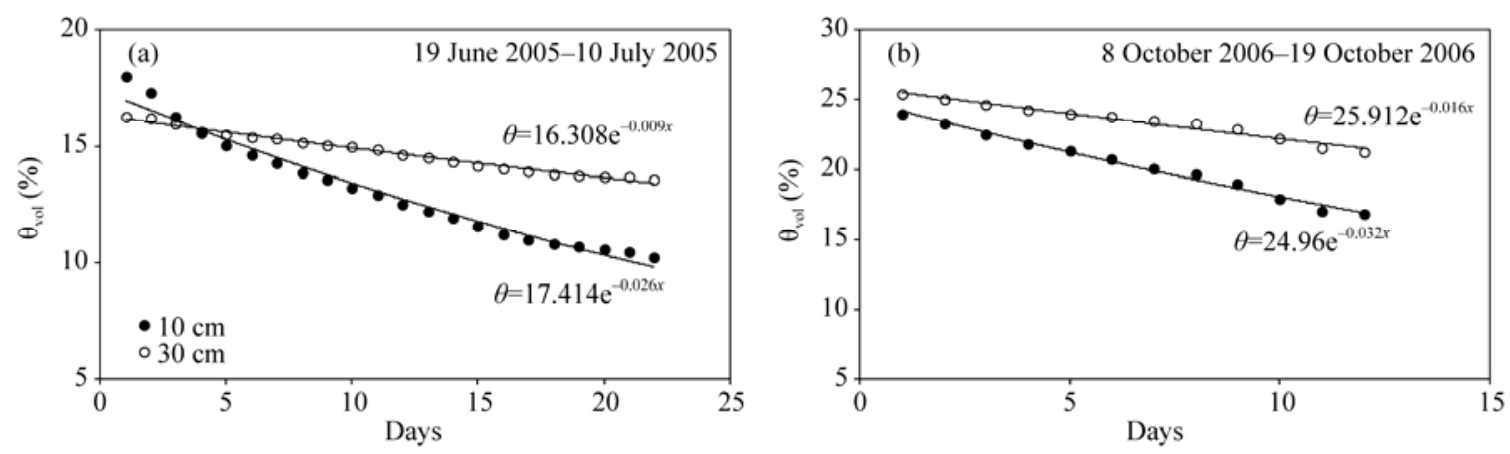

Fig. 4 Observed inter-storm soil moisture dynamics for dry (a) and wet (b) seasons

As shown in the same picture, inter-storm events can be empirically described by an extremely simple negative exponential relation:

$$
\theta(t)=\theta_{0} \exp (-\alpha \times t), \theta_{0}=\theta(t=0),
$$

similar to the formulations used for the description of the streamflow hydrograph recession limb (Wittenberg, 1999).

On a qualitative basis, Fig. 4 also indicates that the rate of the depletion process is smoother in the deeper soil layer, as would have been expected on a conceptual basis, because of the greater inertia against the evapotranspiration process compared with the surface soil layers; evapotranspiration is perhaps the major source of losses during the non-rainy period, especially in the dry summer season. Parameters $\theta_{0}$ and $\alpha$ respectively establish the initial conditions and the rate of the depletion process, and their estimation also gives a quantitative assessment of soil drying velocity.

After estimating values of $\alpha$ for each of the events in question, preliminary exploratory analysis is conducted, and the primary values on which the parameter depends are identified. Parameter $\alpha$ appears to be characterized by variation at both the seasonal and event scales, in addition to variability along the soil profile. The seasonal scale variability is illustrated in Table 1, in which estimates of $\alpha$ are illustrated for the two analyzed soil depths, highlighting the seasons.

Table 1 Seasonal average $\alpha$ estimates for both investigated soil depths

\begin{tabular}{ccccc}
\hline Soil depth & Winter & Spring & Summer & Autumn \\
\hline $10 \mathrm{~cm}$ & 0.019 & 0.043 & 0.030 & 0.021 \\
$30 \mathrm{~cm}$ & 0.013 & 0.017 & 0.016 & 0.016 \\
\hline
\end{tabular}

The most evident and quantitatively assessed difference at this point is the smaller range of variability in $\alpha$ in the deeper layer and its consistency throughout the seasons. In contrast, the rate of the depletion process in the surface layers is highly variable, with great differences among the seasons and with the largest values occurring during the spring, perhaps reflecting the greater water consumption by vegetation during that time of year.

\subsection{Aggregated event scale: implications for mod- elling}

Taken individually, the graphs shown in Fig. 2 do not identify simple empirical relationships that lead to the accurate estimate of actual evapotranspiration. They are however a summary of the direct and indirect relationships between the observed quantities and those calculated from them. Figure 2 also illustrates a qualitative and quantitative representation of the mechanism of switching between the dominant elements controlling evapotranspiration for the climatic conditions in question: the dominant control is the availability of water up to a certain threshold, beyond which the dominant control factor becomes the climate, in particular the temperature and the atmospheric evaporative power. The identified threshold mechanism between ET and $\theta$ is also difficult to use for modelling in this form.

A satisfactory relationship expressed in terms of $\theta$ is obtained when, rather than the volume of ET expressed in $\mathrm{mm}$, the dimensionless ratio $k$ between ET and the potential evapotranspiration (PET) is examined (Figs. 5a and $b$ ).

The dimensionless ratio $k$ is related to the soil water content at the beginning of the event through a power 

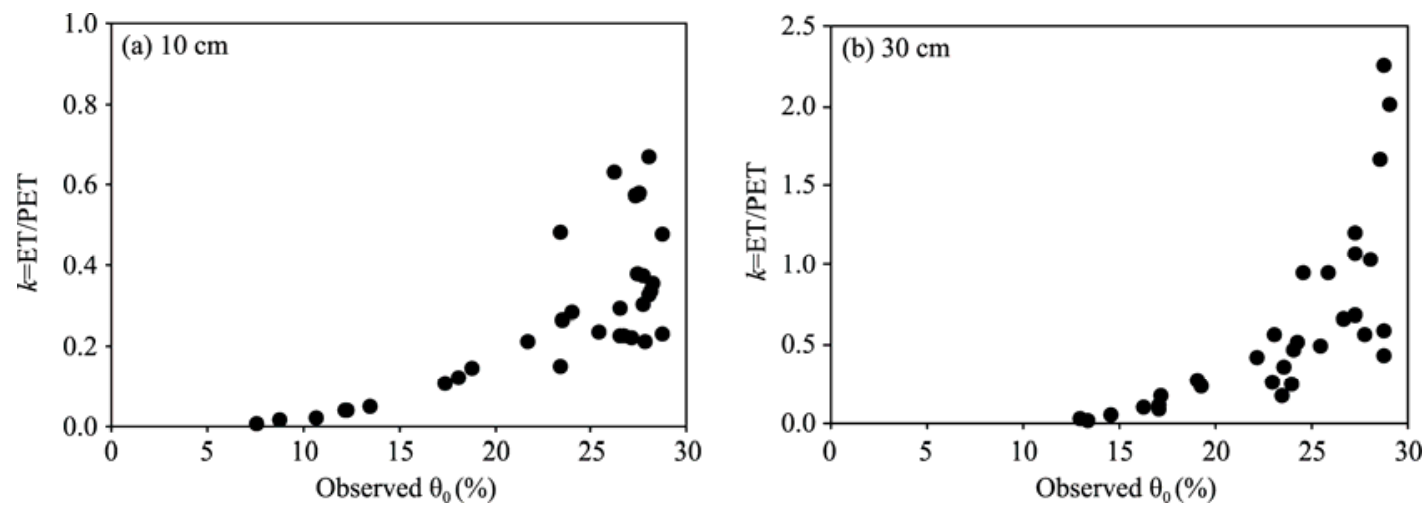

Fig. 5 Scatter plots of observed $\theta_{0}$ data versus dimensionless $k$ ratio. PET, potential evapotranspiration.

relation of the following type:

$$
k=\frac{\mathrm{ET}}{\mathrm{PET}}=a \theta_{0}{ }^{b},
$$

with $a$ being equal to $6 \times 10^{-5}$ and $4 \times 10^{-7}$ and $b 2.61$ and 4.37, respectively, for the 10 and $30 \mathrm{~cm}$ soil depths. The adaptations are quite satisfactory, with an $R^{2}$ of 0.90 and 0.85 , respectively, for the same layers. The potential evapotranspiration was calculated by applying the relation of Penman-Monteith, which proved to be quite suitable for the climatic characterrisation of the site in the model (Khaertdinova and Longobardi, 2013b; Longobardi and Villani, 2013). Similar to the relationship between ET and $\theta_{0}$, Eq. 6 continuously increases, but in contrast, it does not present thresholds or points of discontinuity, making it particularly suitable for a simple empirical model to estimate evapotranspiration for the real site experimental examination. The continuity of the function, which then does not manifest break points, also indicates that the dominant control is the availability of water, at least for the experimental site in question, but this trend could also be typical of the Mediterranean climate.

This approach has a general setting, and the same methodology could be applied to an experimental site with any prior calibration for which a few observations of water content, through the entire related spectrum of variation, would be sufficient. To show this and to measure the ability of the simple descriptive and predictive empirical relation found in Eq. 6, the values of the water content at the end of the event $\theta_{\mathrm{f}}$ are calculated from Eq. 4 and Eq. 6 in the following way:

$$
\theta_{\mathrm{f}}=\theta_{0}-\frac{\mathrm{ET}}{z}=\theta_{0}-\frac{a \theta_{0}{ }^{b} \times \mathrm{PET}}{z},
$$

and are compared with those observed. Eq. 7 has been previously calibrated for fifteen of the thirty analyzed events. Parameters $a$ and $b$ are respectively equal to $5 \times 10^{-5}$ and 2.67 for the $10 \mathrm{~cm}$ depth and $4 \times 10^{-7}$ and 4.39 for the $30 \mathrm{~cm}$ depth, similar to the estimation calibrated for all of the events in Eq. 6. The validation, in terms of comparison between observed and modelled $\theta_{\mathrm{f}}$, is provided for the remaining fifteen events. The comparison is provided in Figs. $6 a$ and $b$.

As a diagnostic of the model, performance metrics, such as MAE (mean absolute error), MSE (mean squared error), RMSE (root mean squared error) and NSE (Nash-Sutcliff efficiency coefficient), were further computed to provide an aggregated but quantitative estimate of model reliability (Table 2 ).

\subsection{Continuous soil moisture dynamics: impli- cations for modelling}

Qualitative and quantitative assessment of the above-discussed inter-storm period dynamics can also represent a useful modelling tool with a conceptual basis for simulating soil moisture dynamics between two subsequent precipitation events through the use of an empirical framework. During inter-storm periods, the variability in soil water content is driven by the loss phenomena, primarily the processes of evapotranspiration and deep drainage. Two primary controls 

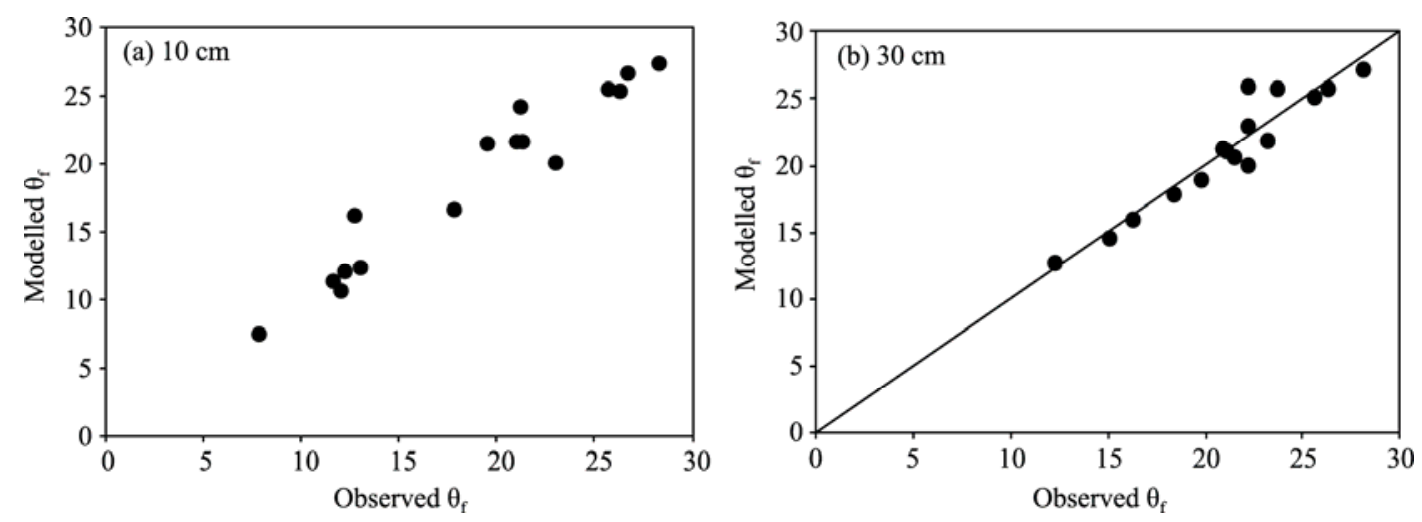

Fig. 6 Scatter plots of observed versus modeled $\theta_{\mathrm{f}}$ data (at the end of the event)

Table 2 Empirical actual evapotranspiration modeling performance metrics (aggregated event scale analysis)

\begin{tabular}{ccccc}
\hline Soil depth & MAE & MSE & RMSE & NSE \\
\hline $10 \mathrm{~cm}$ & 1.10 & 0.42 & 0.16 & 0.93 \\
$30 \mathrm{~cm}$ & 0.95 & 0.04 & 0.05 & 0.89 \\
\hline
\end{tabular}

act on the evapotranspiration process: the atmospheric power of soil water content abstraction, which is a climate control, and the available moisture content, which is a soil water balance control.

If $\alpha$ is linked conceptually to evapotranspiration losses, these two quantities can be directly related through a monotonic relationship without a threshold, unlike the relationship with $\theta_{0}$ as the independent variable; this relationship is of practical use in modelling:

$$
\frac{1}{\alpha}=\mathrm{A} \times \mathrm{ET}^{-\mathrm{B}} \text {. }
$$

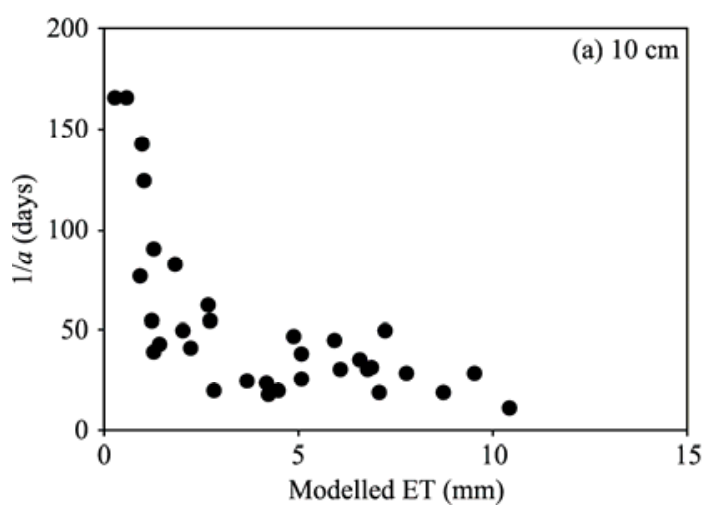

Where $\mathrm{A}$ is equal to 79.71 and 205.12 for the 10 and $30 \mathrm{~cm}$ soil depths, respectively, and B is equal to 0.587 for both soil layers. The relations are shown in Fig. 7: at low volumes of evapotranspiration, the durations of the depletion process are rather long (equal to approximately 150 days at $10 \mathrm{~cm}$ and 300 days at 30 $\mathrm{cm}$ ) and become non-linear rather rapidly (an average of approximately 20 days at $10 \mathrm{~cm}$ or 40 days at 30 $\mathrm{cm}$ ) due to greater ET volumes.

From the practical perspective, using the value of $\theta_{0}$ at the beginning of the inter-storm period, the volume of actual evapotranspiration can be calculated (from Eq. 6) and from this the speed of the process of drying $\alpha$ (from Eq. 8).

For example, for a limited number of events, Fig. 8

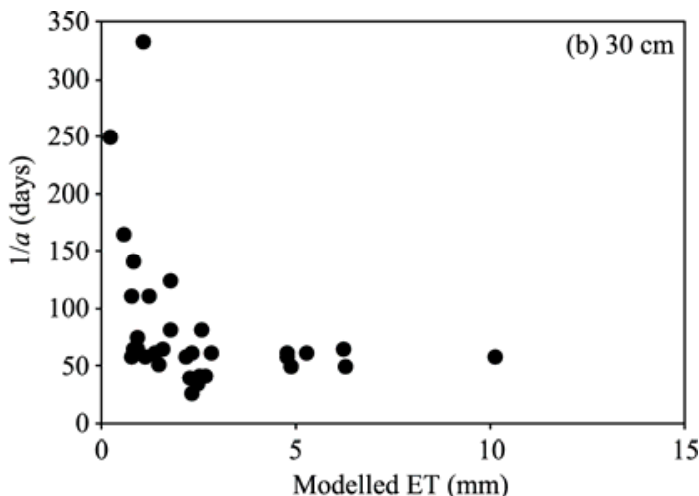

Fig. 7 Parameter $\alpha$ dependence on modeled ET 

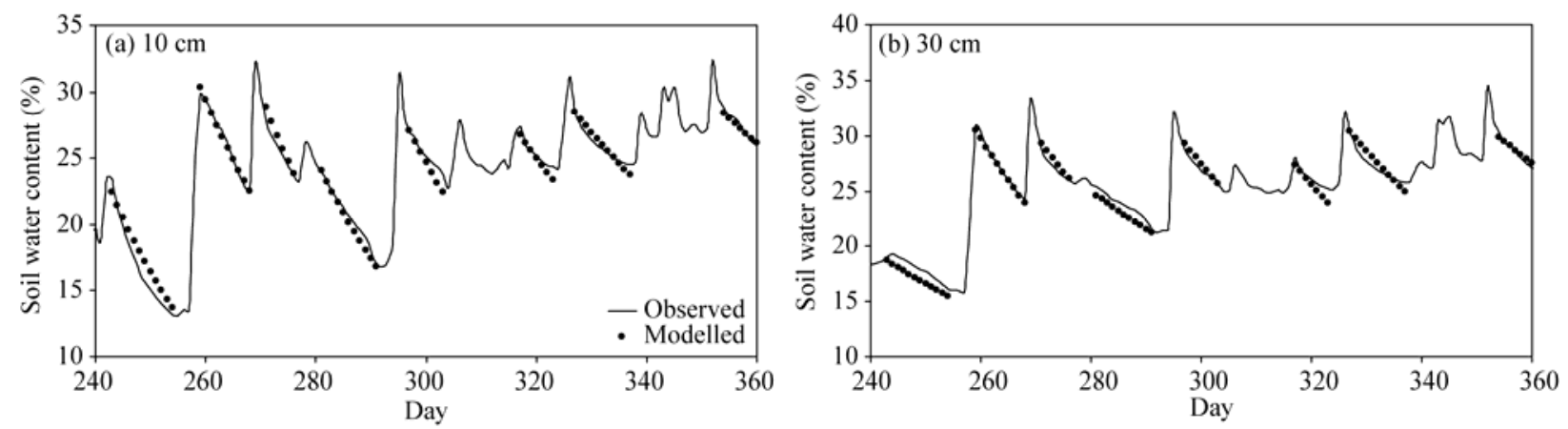

Fig. 8 Temporal patterns of modeled and observed soil water contents

shows the adaptation of the empirical relationship (Eq. 5 ) to the historical series of observed soil water content at both 10 and $30 \mathrm{~cm}$ depths.

The adaptations appear at first visual inspection to be quite satisfactory. To quantify the goodness-of-fit of such an approach, the same parameters calculated in Table 2 are below assessed by comparing the observed values with the value of $\theta_{\mathrm{f}}$ at the end of the event. In the case of the surface layer, the prediction of $\theta_{\mathrm{f}}$ improves, whereas for the daily scale dynamics rather than aggregated events, the metrics are worse for the deepest layer (Table 3).

Table 3 Empirical actual evapotranspiration modeling performance metrics (continuous soil moisture dynamics)

\begin{tabular}{ccccc}
\hline Soil depth & MAE & MSE & RMSE & NSE \\
\hline $10 \mathrm{~cm}$ & 10.750 & 0.290 & 0.078 & 0.88 \\
$30 \mathrm{~cm}$ & 10.214 & 0.194 & 0.063 & 0.91 \\
\hline
\end{tabular}

\section{Conclusions}

This article presented an empirical approach to define the relationships among the water content of the soil, air temperatures and the volumes of actual evapotranspiration in an experimental field located in the south of the Italian peninsula, with a typical Mediterranean climate. Because evapotranspiration is a phenomenon of preponderant importance during the absence of precipitation events, the empirical analysis was conducted with reference to inter-storm events.

In the first step, we discussed the budget at the event scale, estimating for each event the volume of evapotranspiration as the difference between the observations of $\theta$ at the beginning and the end of the event (water balance method) and as a function of $\theta$ and the air temperature. This allowed us to highlight the existence of the dual climate/soil control at the site in question compared with actual evapotranspiration. For the water content, a threshold value was determined below which the control is by soil dynamics and above which the control is by climate dynamics. The switching between the two has been explained in terms of physical properties of the investigated soil texture. Such threshold mechanism, which may create some difficulty from a modelling perspective, can be removed by referencing a dimensionless value of the ET volume. In this second case, the dependence is dictated entirely by the water content, and the adaptability of the empirical equations to the data was very satisfactory. The results summarized here are valid for both soil depths analyzed. Subsequently, by studying the temporal process of the depletion of soil moisture, detailed dynamics during the event were approximated by a negative exponential relationship with respect to time. The empirical analysis showed that the rate of the process is affected by the soil depth and by the climate variability scales. At a seasonal scale, the soil drying process appeared to be more rapid during the spring for the surface layer, perhaps reflecting the higher water consumption by vegetation during this particular period of the year, whereas the rate of depletion appeared to be rather uniformed throughout the year for the deeper layers. During the inter-storm period, soil water content variability is highly driven by evapotranspiration losses, which is controlled by the climate and the soil water balance. Because $\alpha$ is linked conceptually to losses by evapotranspiration, these two quantities were directly related in a monotonic relationship without a threshold, which is of practical use in modelling. This modelling of the dy- 
namics at the event was used in the event scale modelling, and the statistical indicators of performance provide even better results.

\section{Acknowledgments}

The authors gratefully acknowledge funding support provided through the Ministry of Education and Science of the Russian Federation and Italian Ministry of University and Research under the grant ORSA128417. The authors would also thank the anonymous reviewers for their helpful comments, which resulted in a significant improvement of the manuscript.

\section{References}

Brandes D, Wilcox B P. 2000. Evapotranspiration and soil moisture dynamics on a semiarid ponderosa pine hillslope. Journal of the American Water Resources Association, 36: 965-974.

Brena Naranjo J A, Weiler M, Stahl K. 2011. Sensitivity of a data-driven soil water balance model to estimate summer evapotranspiration along a forest chronosequence. Hydrology and Earth System Sciences, 15 : 3461-3473.

Douglas E M, Jacobs J M, Sumner D M, et al. 2009. A comparison of models for estimating potential evapotranspiration for Florida land cover types. Journal of Hydrology, 373: 366-376.

Fisher R A, Williams M, de Lourdes Ruivo M, et al. 2008. Evaluating climatic and soil water controls on evapotranspiration at two Amazonian rainforest sites. Agricultural Forest and Meteorology, 148: $850-861$

Hsieh C I, Huang C W, Kiely G. 2009. Long-term estimation of soil heat flux by single layer soil temperature. International Journal of Biometeorology, 53: 113-123.

Khaertdinova E, Longobardi A. 2013a. Analysis of inter-storm period soil moisture dynamics. Procedia Environmental Sciences, 19: 208-216.

Khaertdinova E, Longobardi A. 2013b. Analysis of inter-storm period evapotranspiration dynamics. In: Proceedings of the $13^{\text {th }}$ International Conference on Environmental Science and Technology. Athens: University of the Aegean, 196-203.

Lakshmi V, Jackson T J, Zehrfuhs D. 2003. Soil moisture-temperature relationships: results from two field experiments. Hydrological Processes, 17: 3041-3057.

Longobardi A, Villani P, Foresta V, et al. 2006. An experimental plot for hydrological processes modelling. In: Proceedings of the $15^{\text {th }}$
IASTED International Conference on Applied Simulation and Modelling. Rhodes, Greece, 195-200.

Longobardi A. 2008. Observing soil moisture temporal variability under fluctuating climatic conditions. Hydrology and Earth System Sciences Discussion, 5: 935-969.

Longobardi A, Villani P. 2013. The use of micrometeorological data to identify significant variables in evapotranspiration modelling. Procedia Environmental Sciences, 19: 267-274.

Nan L, Chen S P, Wilske B, et al. 2011. Evapotranspiration and soil water relationships in a range of disturbed and undisturbed ecosystems in the semi-arid Inner Mongolia, China. Journal of Plant Ecology, 4: 49-60.

Rana G, Katerji N. 2000. Measurement and estimation of actual evapotranspiration in the field under Mediterranean climate: a review. European Journal of Agronomy, 13: 125-153.

Schume H, Jost G, Hager H. 2004. Soil water depletion and recharge patterns in mixed and pure forest stands of European beech and Norway spruce. Journal of Hydrology, 289: 258-274.

Shah N, Ross M, Trout K. 2012. Using soil moisture data to estimate evapotranspiration and development of a physically based root water uptake model. In: Ayse I. Evapotranspiration-Remote Sensing and Modeling. Croatia: InTech, 97-124.

Shang S. 2012. Calculating actual crop evapotranspiration under soil water stress conditions with appropriate numerical methods and time step. Hydrological Processes, 26: 3338-3343.

Suleiman A A, Hoogenboom G. 2007. Comparison of Priestley-Taylor and FAO-56 Penman-Monteith for daily reference evapotranspiration estimation in Georgia. Journal of Irrigation and Drainage Engineering, 133: 175-182.

Tabari H. 2010. Evaluation of reference crop evapotranspiration equations in various climates. Water Resources Management, 24: 2311-2337.

Trajkovic S, Kolakovic S. 2009. Evaluation of reference evapotranspiration equations under humid conditions. Water Resources Management, 23: 3057-3067.

Verhoef A, Fernandez-Galvez J, Diaz-Espejo A, et al. 2006. The diurnal course of soil moisture as measured by various dielectric sensors: effects of soil temperature and the implications for evaporation estimates. Journal of Hydrology, 321: 147-162.

Wilson K B, Hanson P J, Mulholland P J, et al. 2012. A comparison of methods for determining forest evapotranspiration and its components: sap-flow, soil water budget, eddy covariance and catchment water balance. Agricultural and Forest Meteorology, 106: 153-168.

Wittenberg H. 1999. Baseflow recession and recharge as nonlinear storage processes. Hydrological Processes, 13: 715-726. 